\title{
Eficacia del Aloe vera en la respuesta tisular de alveolos post-exodoncia en incisivos de Cavia porcellus
}

\author{
Efficacy of Aloe vera in post-exodontia tissue response in incisors from Cavia porcellus \\ Grisel Yulliana Vadillo Palacios ${ }^{1}$, Luis Alexis Bernuy Torres ${ }^{1,2}$, Cesar Andrés Borja Villanueva ${ }^{1,2}$
}

\section{RESUMEN}

Introducción: En el campo de las plantas medicinales y sus beneficios sobre la salud oral, se hallan investigaciones sobre el Aloe vera, sin embargo, estos se desarrollan principalmente en la observación sobre la inflamación y no en todo el proceso de cicatrización alveolar. Debido a ello, se realiza este estudio de corte cuasi-experimental y longitudinal. Objetivo: Determinar la respuesta tisular de alveolos post-exodoncia en incisivos mandibulares de Cavia porcellus después de la aplicación intra-alveolar de Aloe vera. Materiales y Métodos: Se seleccionaron 24 animales los cuales se dividieron en 2 grupos (experimental y grupo control). La evolución de la respuesta tisular se monitoreó en periodos de 24 horas, 7 y 21 días para cada grupo. Resultados: Se obtuvieron resultados variados en cada periodo, encontrándose una mejora en las fases de reacción de células inflamatorias y granulación, caso contrario en las fases de epitelización y osteogénesis. Conclusión: El Aloe vera presenta un efecto positivo pero estadísticamente no significativo comprobándose su utilidad para la cicatrización en este tipo de herida tan característica en el campo de la odontología.

Palabras clave: Aloe, cicatrización de heridas, cirugía bucal.

\begin{abstract}
Introduction: In the field of medicinal plants and their benefits on oral health, research on Aloe vera is found, however, these are mainly developed in the observation on inflammation and not in the whole process of alveolar healing. As a result, this quasi-experimental and longitudinal study was performed. Objective: To determine the tissue response of alveoli in Cavia porcellus mandibular incisors after intra-alveolar application of Aloe vera. Materials and Methods: Twenty-four animals were selected and divided into 2 groups (experimental and control group). The evolution of the tissue response was evaluated in periods of 24 hours, 7 and 14 days in each group. Results: Several results were obtained in each period, with an improvement in the reaction phases of inflammatory cells and granulation, otherwise in the phases of epithelialization and osteogenesis. Conclusion: The Aloe vera has a positive but statistically non-significant effect proving its usefulness for healing in this type of wound so characteristic in the field of dentistry
\end{abstract}

Keywords: Aloe, wound healing, oral surgery.

${ }^{1}$ Universidad Nacional Mayor de San Marcos. Lima - Perú.

${ }^{2}$ Universidad Privada Juan Pablo II. Lima - Perú.

\section{INTRODUCCIÓN}

La cicatrización de los tejidos y el control de la inflamación son procesos de gran importancia y constituyen uno de los pilares para asegurar el éxito de cualquier tipo de tratamiento en el área de la cirugía oral. En esta línea de investigación se hallan estudios sobre los beneficios del uso de plantas tradicionales, en los cuales destaca el Aloe vera (1). En el campo de la periodoncia se le aplica en forma de enjuagues bucales y pastas dentales obteniéndose resultados satisfactorios. Sin embargo, los resultados de las investigaciones no son concluyentes (2,3). En la presente investigación se planteó la hipótesis de que el relleno alveolar a base de Aloe vera favorece la respuesta tisular en alveolos dentarios post exodoncia en incisivos de Cavia porcellus.

La extracción dentaria reúne una serie de características que la convierten en una herida única, en primer lugar puede ser considerada como un fractura abierta, es decir, hay ruptura del recubrimiento superficial, que deja expuesto al hueso. En segundo lugar, es posible considerarla como una herida infectada, pues se abre a una cavidad séptica donde conviven, aunque 
normalmente en un estado saprofítico, una gran variedad de gérmenes que pueden romper su equilibrio ecológico ante el hecho traumático de la extracción. En tercer lugar, se puede considerar como una fractura con pérdida de sustancia ya que la avulsión dentaria irrumpe definitivamente la solución de la continuidad ósea (4). A pesar de todo esto, la cicatrización de una herida post extracción no difiere de otras heridas del cuerpo excepto que es modificada por la situación anatómica particular que existe después de la extirpación de un diente.

El gel de Aloe vera se obtiene de las hojas carnosas que desprenden un jugo gelatinoso transparente y de sabor insípido. Está formado por una mezcla de más de 20 sustancias, como polisacáridos, glucósidos, enzimas y minerales. A diferencia del acíbar, el gel de aloe no tiene propiedades laxantes sino que regula la digestión. Sus principales componentes activos son vitaminas A, C, E, tiamina, niacina, riboflavina, colina, ácido fólico, B12; enzimas como amilasa, fosfatasa alcalina, lipasa, carboxipeptidasa; antraquinonas como barbaloina, aloina, antronas, cromonas, o aminoácidos como lisina, valina, leucina y metionina (5).

Un $99.4 \%$ del peso del gel de aloe es agua. Más del $60 \%$ de los sólidos totales son polisacáridos mucilaginosos ligados a azucares. El mucílago está compuesto de diferentes polisacáridos neutros, ácidos y acetilatos responsables de la gran capacidad que tiene la planta para retener agua gracias a la cual puede sobrevivir en condiciones de sequía (5).

La presente investigación tuvo como objetivo principal determinar la eficacia del relleno alveolar a base del gel de aloe sobre la respuesta tisular en alveolos post-exodoncia en incisivos de Cavia porcellus. Para ello se evaluó la respuesta celular inflamatoria, la presencia de tejido de granulación, epitelización y osteogénesis.

\section{MATERIALES Y MÉTODOS}

El presente estudio fue de tipo cuasi experimental y longitudinal. Se realizó en las instalaciones del Programa de Crianza de Animales Menores de la Universidad Nacional Agraria de La Molina. Se tomó una muestra de 24 ejemplares de Cavia porcellus, con los siguientes criterios de selección: a) peso de 700 a 900 gramos, b) edad de 4 a 6 meses de nacido, c) no presentar ninguna enfermedad, y d) pertenecer a una misma camada.

Una vez seleccionados los animales para la experimentación se procedió a dividirlos en dos jaulas de 16 cuyes cada una, con su respectiva división individual para cada animal.

Para el ensayo se consideraron dos grupos: A (grupo control, sin aplicación de relleno) y B (grupo al que se le aplicó relleno alveolar a base de gel de aloe). Cada grupo se subdividió en 3 subgrupos de 4 integrantes cada uno, ya que se consideraron observaciones a las 24 h, 7 y 21 días. Se les administró $0.1 \mathrm{~mL}$ de ketamina IM con una jeringa de $1 \mathrm{ml}$. Luego se les diferenció registrando el número de arete correspondiente.

Una vez concretada la sedación se realizó el lavado del área adyacente a la zona quirúrgica con clorexidrina al $2 \%$. Luego se procedió a la infiltración de anestesia local a la zona de los incisivos con lidocaína al 2\% utilizando una cárpule y aguja dental corta. Se procedió a realizar la técnica convencional de exodoncias: debridar el diente con botador recto delgado para luego realizar la extracción dentaria con fórceps. Se realizó la irrigación de la herida con suero fisiológico. Se colocó el relleno alveolar al grupo experimental. Finalmente se afrontó los bordes de la herida y se suturó con seda negra trenzada 5/00.

Al terminar el procedimiento quirúrgico los animales fueron devueltos a sus respectivas jaulas y observadas dos horas después de la cirugía. El primer día después post-exodoncia, los animales recibieron alimento disuelto en agua, al segundo día volvieron a su dieta normal.

Los datos obtenidos en la observación de los cambios tisulares ocurridos en cada corte histológico se ordenaron en una matriz realizada en el programa estadístico SPSS aplicando pruebas de estadística descriptiva y estadística inferencial no paramétrica Chi cuadrado.

\section{RESULTADOS}

La observación de la respuesta tisular postexodoncia, se realizó mediante la observación de 4 dimensiones, las cuales son:

1) reacción de células inflamatorias

2) granulación

3) epitelización

4) osteogénesis.

Se realizaron en tres cortes de tiempo: 24 horas, 7 días y 21 días. En el estudio de la reacción de células inflamatorias se consideró los siguientes indicadores:

a) cantidad de leucocitos polimorfonucleares (lpmn),

b) cantidad de linfocitos $y$,

c) cantidad de macrófagos, obteniéndose los siguientes resultados: 
Tabla 1. Reacción de células inflamatorias, de granulación y osteogénesis según el tipo de relleno alveolar en 24 h, 7 y 14 días en alveolos post-exodoncia de Cavia porcellus

\begin{tabular}{|c|c|c|c|c|c|c|c|c|c|c|c|}
\hline \multicolumn{12}{|c|}{ Reacción de células inflamatorias según el tipo de relleno alveolar en 24 h, 7 y 21 días } \\
\hline \multirow{2}{*}{ Tiempo } & \multirow{2}{*}{\multicolumn{2}{|c|}{\begin{tabular}{|l|l|} 
Tipo de relleno \\
\end{tabular}}} & \multicolumn{3}{|c|}{ Cantidad de lpmn } & \multicolumn{3}{|c|}{\begin{tabular}{|l|} 
Cantidad de linfocitos \\
\end{tabular}} & \multicolumn{3}{|c|}{ Cantidad de macrófagos } \\
\hline & & & Escaso & Moderado & Abundante & Escaso & Moderado & Abundante & Escaso & Moderado & Abundante \\
\hline \multirow{4}{*}{24 horas } & \multirow{2}{*}{ Control } & Frecuenc & 0 & 0 & 4 & 3 & 1 & 0 & 0 & 4 & 0 \\
\hline & & $\%$ & $0.00 \%$ & $0.00 \%$ & $100.00 \%$ & $75.00 \%$ & $25.00 \%$ & $0.00 \%$ & $0.00 \%$ & $100.00 \%$ & $0.00 \%$ \\
\hline & \multirow{2}{*}{ Aloe } & Frecuenc & 0 & 2 & 2 & 4 & 0 & 0 & 1 & 3 & 0 \\
\hline & & $\%$ & $0.00 \%$ & $50.00 \%$ & $50.00 \%$ & $100 \%$ & $0.00 \%$ & $0.00 \%$ & $25.00 \%$ & $75.00 \%$ & $0.00 \%$ \\
\hline \multirow{4}{*}{7 días } & \multirow{2}{*}{ Control } & Frecuenc & 0 & 0 & 4 & 4 & 0 & 0 & 0 & 4 & 0 \\
\hline & & $\%$ & $0.00 \%$ & $0.00 \%$ & $100.00 \%$ & $100 \%$ & $0.00 \%$ & $0.00 \%$ & $0.00 \%$ & $100.00 \%$ & $0.00 \%$ \\
\hline & \multirow{2}{*}{ Aloe } & Frecuenc & 1 & 1 & 2 & 4 & 0 & 0 & 3 & 1 & 0 \\
\hline & & $\%$ & $25.00 \%$ & $25.00 \%$ & $50.00 \%$ & $100 \%$ & $0.00 \%$ & $0.00 \%$ & $75.00 \%$ & $25.00 \%$ & $0.00 \%$ \\
\hline \multirow{4}{*}{21 días } & \multirow{2}{*}{ Control } & Frecuenc & 0 & 1 & 3 & 2 & 2 & 0 & 0 & 4 & 0 \\
\hline & & $\%$ & $0.00 \%$ & $25.00 \%$ & $75.00 \%$ & $50.00 \%$ & $50.00 \%$ & $0.00 \%$ & $0.00 \%$ & $100.00 \%$ & $0.00 \%$ \\
\hline & \multirow[b]{2}{*}{ Aloe } & Frecuenc & 0 & 0 & 4 & 3 & 1 & 0 & 1 & 0 & 3 \\
\hline & & $\%$ & $0.00 \%$ & $0.00 \%$ & $100.00 \%$ & $75.00 \%$ & $25.00 \%$ & $0.00 \%$ & $25.00 \%$ & $0.00 \%$ & $75.00 \%$ \\
\hline \multicolumn{12}{|c|}{ Granulación se } \\
\hline \multirow{2}{*}{\begin{tabular}{|c|} 
Tiempo de \\
observación
\end{tabular}} & \multirow{2}{*}{\multicolumn{2}{|c|}{ Tipo de Relleno Alveolar }} & \multicolumn{3}{|c|}{ Cantidad de fibroblastos } & \multicolumn{3}{|c|}{ Cantidad de fibras colágenas } & \multicolumn{3}{|c|}{ Cantidad de capilares } \\
\hline & & & Escaso & Moderado & Abundante & Escaso & Moderado & Abundante & Escaso & Moderado & Abundante \\
\hline & & Frecuenc & 0 & 0 & 4 & 0 & 3 & 1 & 1 & 3 & 0 \\
\hline & Control & $\%$ & $0.00 \%$ & $0.00 \%$ & $100.00 \%$ & $0.00 \%$ & $75.00 \%$ & $25.00 \%$ & $25 \%$ & $75.00 \%$ & $0.00 \%$ \\
\hline & & Frecuer & 3 & 1 & 0 & 3 & 1 & 0 & 4 & 0 & 0 \\
\hline & & $\%$ & $75 \%$ & $25.00 \%$ & $0.00 \%$ & $75 \%$ & & $0.00 \%$ & $100 \%$ & $0.00 \%$ & $0.00 \%$ \\
\hline & & Frecuenc & 0 & 4 & 0 & 3 & 1 & 0 & 4 & 0 & 0 \\
\hline & & $\%$ & $0.00 \%$ & $100.00 \%$ & $0.00 \%$ & $75 \%$ & $25.00 \%$ & $0.00 \%$ & $100 \%$ & $0.00 \%$ & $0.00 \%$ \\
\hline I dias & & recuenc & 0 & 3 & 1 & 2 & 2 & 0 & 3 & 1 & 0 \\
\hline & & $\%$ & $0.00 \%$ & $75.00 \%$ & $25.00 \%$ & $50 \%$ & $50.00 \%$ & $0.00 \%$ & $75 \%$ & $25.00 \%$ & $0.00 \%$ \\
\hline & & Frecue & 0 & 3 & 1 & 4 & 0 & 0 & 1 & 3 & 0 \\
\hline & & $\%$ & $0.00 \%$ & $75.00 \%$ & $25.00 \%$ & $100 \%$ & $0.00 \%$ & $0.00 \%$ & $25 \%$ & $75.00 \%$ & $0.00 \%$ \\
\hline 1 días & & Frecue & 3 & 1 & 0 & 3 & 1 & 0 & 0 & 1 & 3 \\
\hline & & $\%$ & $75 \%$ & $25.00 \%$ & $0.00 \%$ & $75 \%$ & $25.00 \%$ & $0.00 \%$ & $0.00 \%$ & $25.00 \%$ & $75.00 \%$ \\
\hline & & & oún ol & & nollome r r t & glveole & & $\ln 7 \mathrm{v}^{2}$ & 1 días & & \\
\hline Tiempo de & & & Cantida & de os & os & Cantidad & de ost & tos & Cantida & $\mathrm{ad} \mathrm{de} \mathrm{t}$ & teoide \\
\hline observación & & & \begin{tabular}{|l|} 
escaso \\
\end{tabular} & moderado & abundante & escaso & moderado & abundante & \begin{tabular}{|l|} 
escaso \\
\end{tabular} & moderado & Abundante \\
\hline & & Frecuen & 2 & 2 & 0 & 4 & 0 & 0 & 4 & 0 & 0 \\
\hline & & $\%$ & $50.00 \%$ & $50.00 \%$ & $0.00 \%$ & $100 \%$ & $0.00 \%$ & $0.00 \%$ & $100 \%$ & $0.00 \%$ & $0.00 \%$ \\
\hline 24 noras & & Frecuen & 1 & 1 & 2 & 1 & 3 & 0 & 4 & 0 & 0 \\
\hline & Aloe vera & $\%$ & $25.00 \%$ & $25.00 \%$ & $50.00 \%$ & $25.00 \%$ & $75.00 \%$ & $0.00 \%$ & $100 \%$ & $0.00 \%$ & $0.00 \%$ \\
\hline & & Frecuen & 2 & 1 & 1 & 0 & 4 & 0 & 4 & 0 & 0 \\
\hline & & $\%$ & $50.00 \%$ & $25.00 \%$ & $25.00 \%$ & $0.00 \%$ & $100.00 \%$ & $0.00 \%$ & $100 \%$ & $0.00 \%$ & $0.00 \%$ \\
\hline / dias & & Frecuen & 3 & 1 & 0 & 3 & 0 & 1 & 3 & 1 & 0 \\
\hline & & $\%$ & $75.00 \%$ & $25.00 \%$ & $0.00 \%$ & $75.00 \%$ & $0.00 \%$ & $25.00 \%$ & $75.00 \%$ & $25.00 \%$ & $0.00 \%$ \\
\hline & & Frecuenc & 0 & 4 & 0 & 0 & 3 & 1 & 4 & 0 & 0 \\
\hline & Control & $\%$ & $0.00 \%$ & $100.00 \%$ & $0.00 \%$ & $0.00 \%$ & $75.00 \%$ & $25.00 \%$ & $100 \%$ & $0.00 \%$ & $0.00 \%$ \\
\hline 21 dias & & Frecuen & 0 & 4 & 0 & 1 & 2 & 1 & 3 & 1 & 0 \\
\hline & & $\%$ & $0.00 \%$ & $100.00 \%$ & $0.00 \%$ & $25.00 \%$ & $50.00 \%$ & $25.00 \%$ & $75.00 \%$ & $25.00 \%$ & $0.00 \%$ \\
\hline
\end{tabular}


Tabla 2. Epitelización según el tipo de relleno alveolar en 24 h, 7 y 21 días en alveolos post-exodoncia de Cavia porcellus

\begin{tabular}{|c|c|c|c|c|c|c|c|}
\hline \multirow{2}{*}{$\begin{array}{l}\text { Tiempo de } \\
\text { observación }\end{array}$} & \multirow{2}{*}{\multicolumn{2}{|c|}{ Tipo de Relleno Alveolar }} & \multicolumn{3}{|c|}{ Cantidad de células epiteliales } & \multicolumn{2}{|c|}{ Migración de c. epiteliales } \\
\hline & & & Escaso & Moderado & Abundante & Escaso & Moderado \\
\hline \multirow[t]{4}{*}{24 horas } & Control & Frecuencia & 2 & 2 & 0 & 4 & 0 \\
\hline & & $\%$ & $50.0 \%$ & $50.0 \%$ & $.0 \%$ & $100.0 \%$ & $.0 \%$ \\
\hline & Aloe & Frecuencia & 0 & 3 & 1 & 4 & \\
\hline & & $\%$ & $.0 \%$ & $75.0 \%$ & $25.0 \%$ & $100.0 \%$ & $.0 \%$ \\
\hline \multirow[t]{4}{*}{7 días } & Control & Frecuencia & 1 & 3 & 0 & 4 & \\
\hline & & $\%$ & $25.0 \%$ & $75.0 \%$ & $.0 \%$ & $100.0 \%$ & $.0 \%$ \\
\hline & Aloe & Frecuencia & 1 & 2 & 1 & 3 & 1 \\
\hline & & $\%$ & $25.0 \%$ & $50.0 \%$ & $25.0 \%$ & $75.0 \%$ & $25.0 \%$ \\
\hline \multirow[t]{4}{*}{21 días } & Control & Frecuencia & 4 & 0 & 0 & 4 & 0 \\
\hline & & $\%$ & $100.0 \%$ & $.0 \%$ & $.0 \%$ & $100.0 \%$ & $.0 \%$ \\
\hline & Aloe & Frecuencia & 4 & 0 & 0 & 3 & 1 \\
\hline & & $\%$ & $100.0 \%$ & $.0 \%$ & $.0 \%$ & $75.0 \%$ & $25.0 \%$ \\
\hline
\end{tabular}

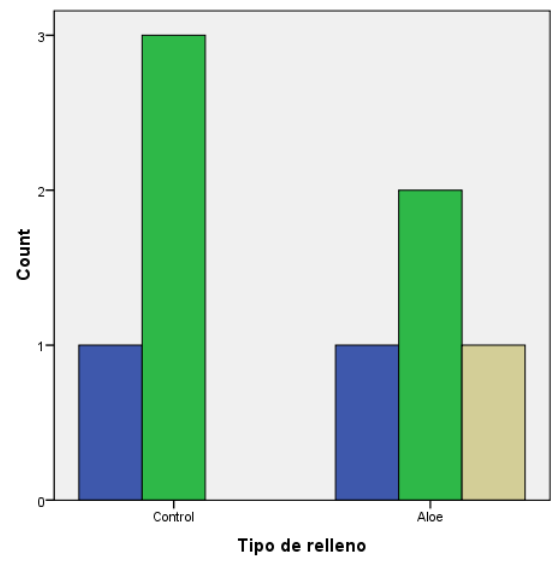

Gráfico 1. Cantidad de LPMN según el tipo de relleno alveolar en $24 \mathrm{~h}$

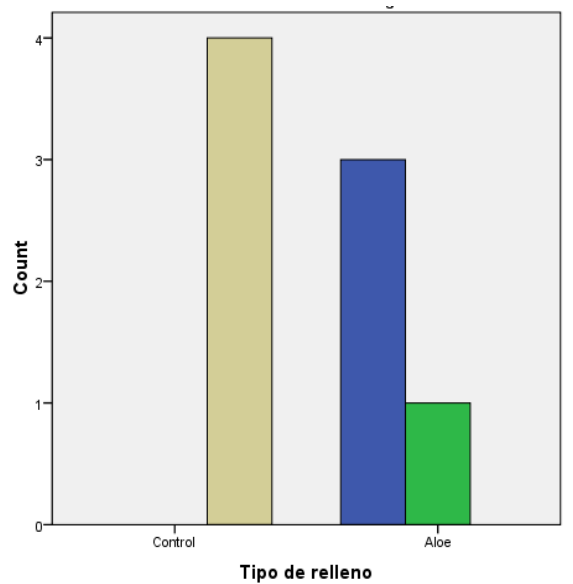

Gráfico 3. Cantidad de fibroblastos según relleno alveolar en $24 \mathrm{~h}$

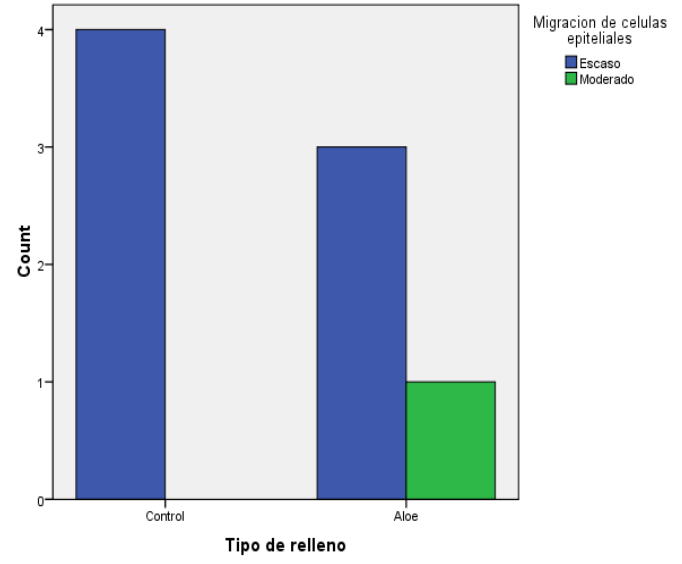

Gráfico 2. Cantidad de linfocitos según relleno alveolar a los $\mathbf{1 4}$ días

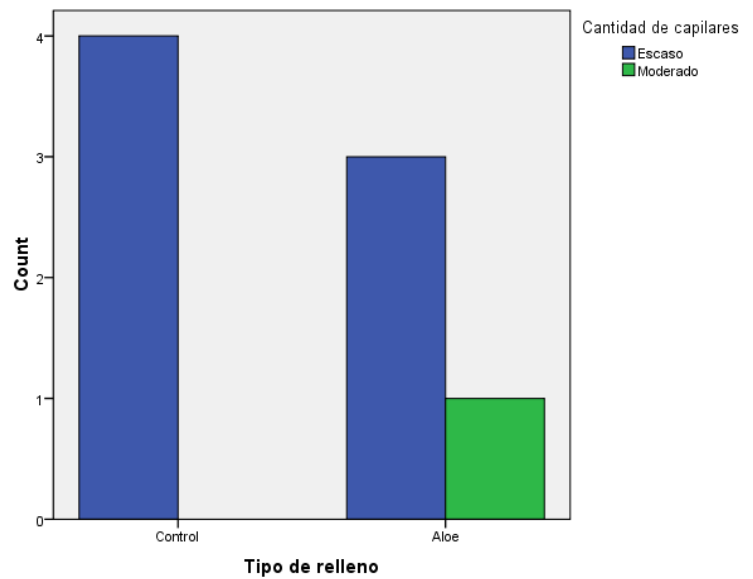

Gráfico 4. Cantidad de capilares según relleno alveolar en 7 días 
Eficacia del Aloe vera en la respuesta tisular de alveolos post-exodoncia en incisivos de Cavia porcellus Vadillo Palacios, Bernuy Torres y Borja Villanueva

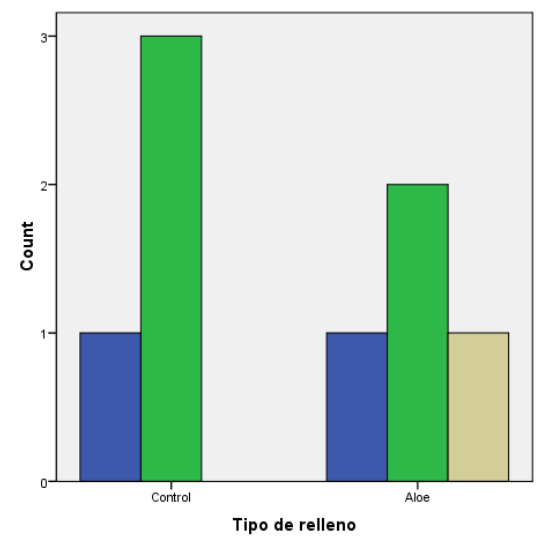

Gráfico 5. Cantidad de células epiteliales según relleno alveolar en 7 días

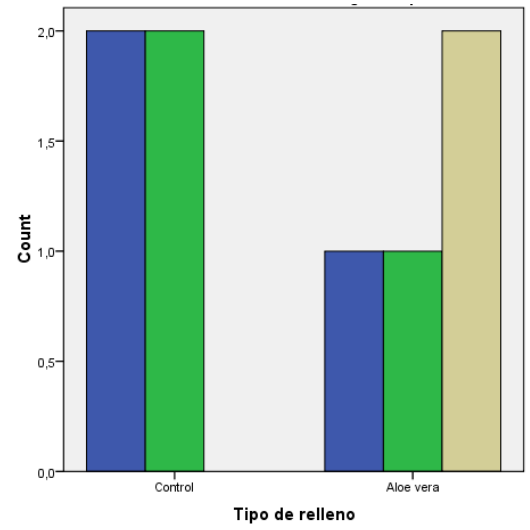

Gráfico 5. Cantidad de osteoblastos según el tipo de rellenos a las $24 \mathrm{~h}$

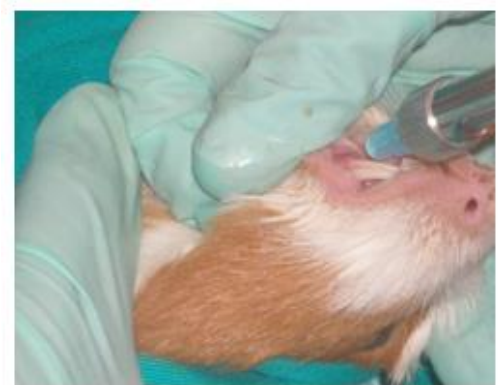

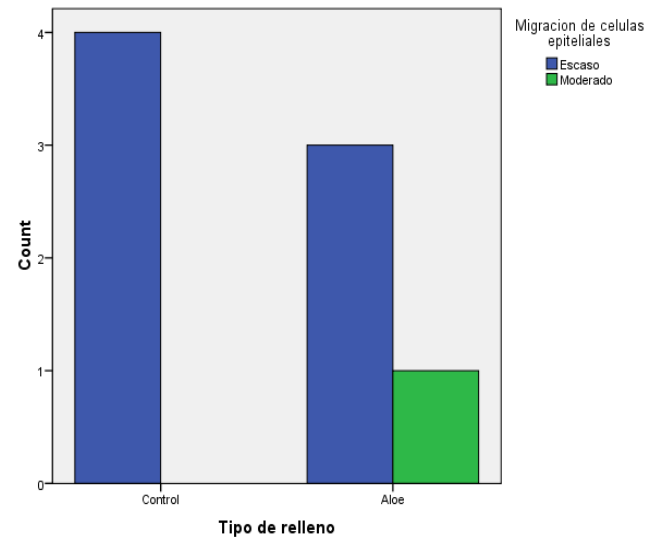

Gráfico 6. Migración de células epiteliales según relleno alveolar en 14 días

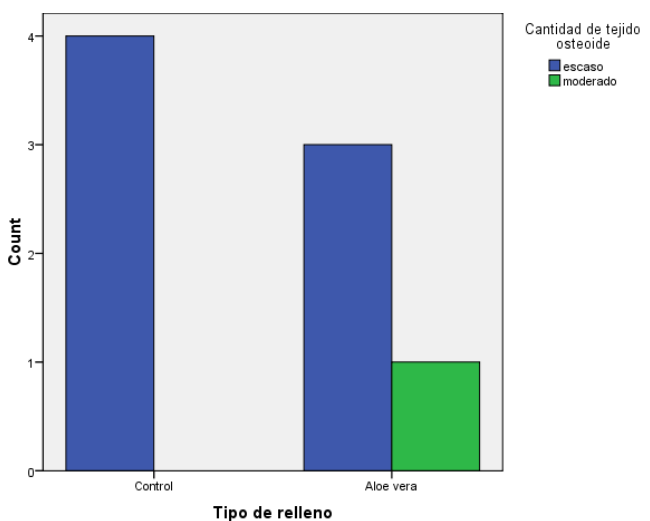

Gráfico 6. Cantidad de tejido osteoide según tipo de relleno a los 21 días

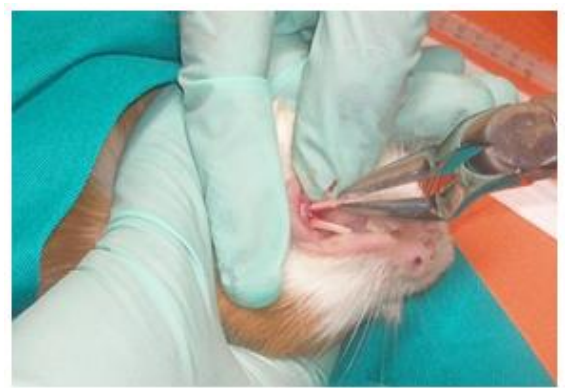

Fig. 1. Anestesia y extracción dental en Cavia porcellus

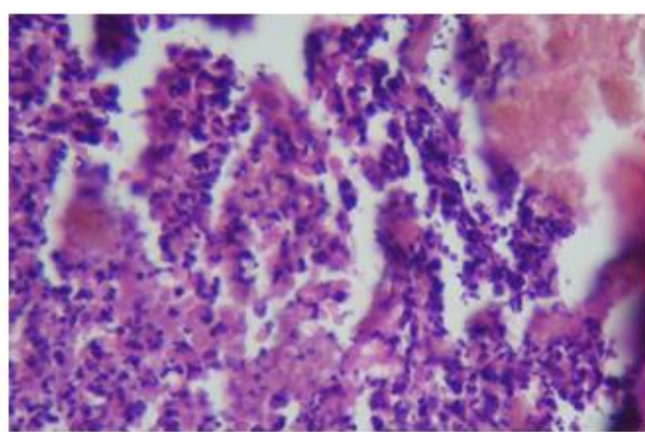

Fig. 2. Predominio de LPMN en presencia de relleno alveolar Aloe vera a las 24 h (20X)

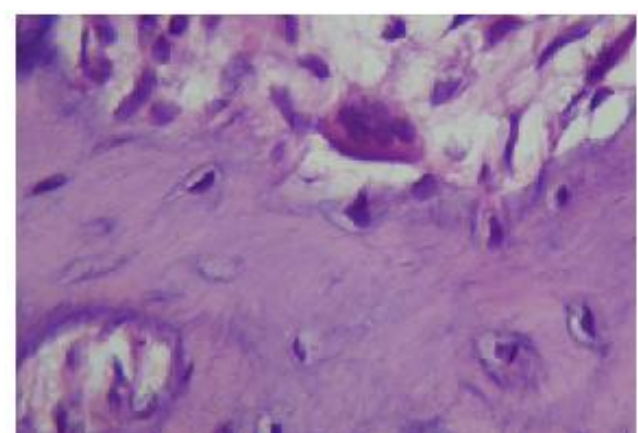

Fig. 3. Presencia de escasos macrófagos en presencia de relleno epitelial Aloe vera a los 7 días $(40 \mathrm{X})$ 


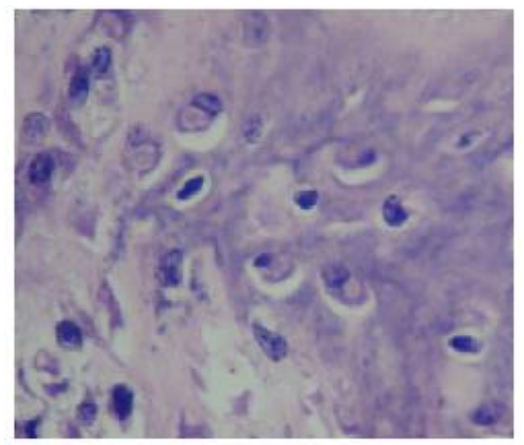

Fig. 4. Proliferación de tejido osteoide en presencia de relleno alveolar a base de Aloe vera a los 28 días $(40 \mathrm{X})$

\section{DISCUSIÓN}

Para el análisis de los resultados observados se debe de considerar que cada del proceso de cicatrización tiene un periodo de mayor actividad, así mismo, todas se presentan superpuestas en el proceso de cicatrización (7-10) no teniendo un inicio o fin claramente diferenciado. Se han realizado numerosas investigaciones sobre las propiedades y aplicaciones del Aloe vera a nivel de la cavidad oral, sin embargo, la gran mayoría de ellas se observan solamente su propiedad antiinflamatoria a un nivel clínico (11-13). De esta manera se destaca que a las $24 \mathrm{~h}$ post-exodoncia en la fase inflamatoria, el Aloe vera produjo una disminución en la cantidad de LPMN, linfocitos y macrófagos con respecto al control, coincidiendo con otros estudios sobre Aloe vera $(11,14)$ a nivel clínico e histológico que encontraron actividad anti-inflamatoria 24 h después de la cirugía. Cabe destacar que estos resultados discrepan con la investigación de Espíritu Huamán quien no evidencio mejoría en el proceso inflamatorio a las $24 \mathrm{~h}$ (15). Los resultados obtenidos a las $24 \mathrm{~h}$ muestran un proceso favorable en el control de la inflamación por parte de ambos rellenos, sin embargo, no se encontró asociación estadística ( $\mathrm{p}$ $=0.105$ ). A pesar de ello, en la evolución del proceso se halló asociación entre la presencia y proliferación de macrófagos con el tipo de relleno alveolar solo a los 7 días, desapareciendo posteriormente.

En la fase de granulación, observada a los 7 días, se halló un aumento de sus elementos (fibroblasto, fibras colágenas y capilares) para el grupo de relleno alveolar de Aloe vera con respecto al grupo control. Se observó concordancia con trabajos de Aloe vera $(14,16)$, al igual que con Espíritu en el año 2002 cuyo análisis histológico arrojo resultados semejantes a los 7

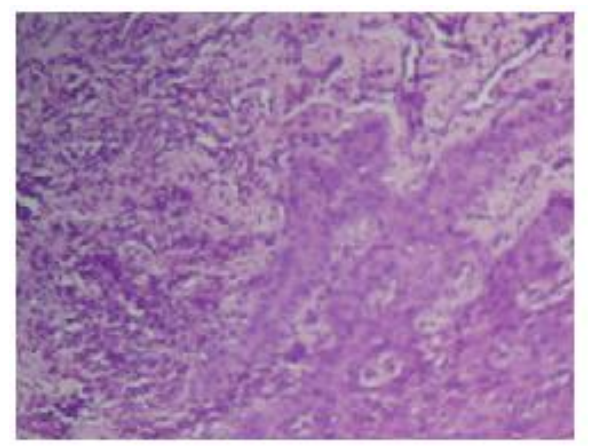

Fig. 5. Migración de células epiteliales en presencia de relleno epitelial de Aloe vera a los 28 días (10X)

días, sin embargo, se debe destacar que la investigación mencionada se realizó en canes.

La epitelización fue observada y se consideró como indicador a las células epiteliales tanto en su migración como proliferación, no hallándose diferencias significativas entre el grupo control y el grupo de relleno experimental $(\mathrm{p}=0.23)$, lo cual coincidió con las observaciones clínicas que se le realizaron a los sujetos de experimentación. Otros trabajos de investigación de índole histológico (11) encontrados no profundizaron sobre este aspecto de la cicatrización debido posiblemente a que no superaron los 15 días de observación. Cabe destacar que no existió asociación entre los indicadores y el tipo de relleno alveolar, en ninguno de los tiempos de observación, sin embargo, se observó una tendencia ligeramente favorable a las 24 h y 7 días.

En el proceso de osteogénesis, a los 28 días se encontró gran actividad por parte de los osteoblastos y osteoclastos, destacando en el grupo Aloe vera. En concordancia con estos sucesos se evidenció que tanto para el grupo de relleno de Aloe vera como de grupo control, el tejido osteoide fue en cantidad preponderantemente escaso y en pocos casos moderado.

\section{CONCLUSIONES}

La respuesta tisular en los alveolos postexodoncia fue favorecida por los rellenos de Aloe vera con respecto al control, sin embargo no se encontró asociación estadística. Por otro lado, la respuesta celular inflamatoria, el proceso de granulación, epitelizacion y osteogenesis fueron favorecidos por parte del relleno de Aloe vera, sin embargo, no se encontró asociación estadística. 


\section{AUTOR DE CORRESPONDENCIA}

CD Cesar Andres Borja Villanueva

Universidad Privada Juan Pablo II

E-mail: abv1979@gmail.com

\section{REFERENCIAS BIBLIOGRÁFICAS}

1. Lacaze D. Experiencias en medicina tradicional y salud intercultural en la Amazonía ecuatoriana. 2002 Anales, ISSN 1101-4148, №. 5. págs. 163-194

2. Villalobos O. Efecto de un enjuague bucal compuesto de aloe vera en la placa bacteriana e inflamación gingival. 2001 Acta odontol. venez v.39 n.2

3. Avilés R. Propiedades Antiinflamatorias del Aloe Vera en Tejido Blando de Cavia porcellus in Vivo. Tesis Bachiller. Universidad de San Martín de Porres. FacOdontología. Perú 1994.

4. Felzani R. Cicatrización De Los Tejidos Con Interés En Cirugía Bucal: Revisión De La Literatura. Rev. Acta Odontológica Venezolana. Volumen $43 \mathrm{~N}^{\mathrm{o}} 3$ / 2005

5. Pareja B. Plantas medicinales. Dermofarmacia. Folia Dermatológica Peruana - Vol. 12 No. 1 Abril 2001

6. Franco C, Muñoz D, Gomez C. Caracteristicas fitoquimicas y capacidad antioxidante in vitro de Aloe vera, Plukenetia volubilibs, Caiophora carduifolia, Cecropia membranácea. 2016. Anales de la Facultad de Medicina. Vol 77 No 1.

7. Lindhe, J. Periodontología. Clínica. Argentina: Editorial Panamericana. 1996

8. Laskin Daniel M. Extracción de Dientes, Editorial Panamericana Argentina 1995

9. Bhaskar. Histología y Embriología bucal. $11^{\circ}$ edición. Editorial Mosby. México 1993

10. Bazán C. Tratamiento de la enfermedad gingival mediante la aplicación tópica sulcular del gel Aloe vera en pacientes con retardo mental, Tesis Bachiller. Universidad de San Martín de Porres. Facultad de Odontología. Perú 2000

11. Yovera J. El aloe vera en el post operatorio de las exodoncias de terceras molares inferiores retenidas. Tesis Bachiller. Universidad de San Martín de Porres. Perú 2002

12. King J. Efecto antiinflamatorio $\mathrm{y}$ regenerativo del gel de aloe vera aplicado tópicamente en bolsas periodontales, en paciente con periodontitis tratados en la Facultad de Odontologia de la Universidad de San Carlos de Guatemala. Tesis de licenciatura. 2016

13. Santos L. Efecto Clínico del Gel aloe vera en pacientes con gingivitis asociada a placa dental solamente. Tesis Bachiller. Universidad Nacional Federico Villarreal.Perú 2006

14. Espíritu L. Estudio Histológico de la respuesta inflamatoria y cicatrizante del uso de apósitos de sábila en Heridas post extracción dental en perros. Tesis Bachiller. Universidad Nacional Federico Villarreal. Facultad de Odontología. Perú 2002. 